\title{
La narrativa imaginativa como vía de acceso a la solidaridad. Una propuesta educativa desde el pragmatismo y el neopragmatismo*
}

\author{
Martha J. Patiño**
}

Recibido: 24 de noviembre de 2017

Evaluado: 23 de febrero 2018

Aceptado: 16 de abril de 2018

\section{RESUMEN}

Este artículo plantea la necesidad de reconocer las formas de narrativa presentes en los procesos educativos, y plantea la necesidad de integración de otra forma más sutil y orientada a la educación de la sensibilidad para la solidaridad, ya que se parte de la hipótesis que sostiene que los individuos se educan en dos formas particularmente poderosas de racionalidad, que derivan una insensibilización hacia los demás y hacia la naturaleza, evidenciado en egoísmo radical, en el consumismo inconsciente, en la exclusión de los demás y en la destrucción de la naturaleza. Como método de análisis, se examina el problema a la luz de la crítica al pensar objetivo-positivo, desde el pragmatismo clásico de Dewey y el neopragmatismo de Rorty, del mismo modo que se presenta la correspondiente crítica a la razón instrumental-tecnológica desde la escuela de Frankfurt. Todo lo anterior con la finalidad de ofrecer una propuesta de un léxico, una narrativa imaginativa que se oriente hacia la creación de un ethos de la empatía y la solidaridad, el cual se considera una perspectiva utópica, posible solo en la medida en que se haga visible otro ámbito de lo humano, para hacer posible el progreso moral que como humanidad constituye nuestra responsabilidad.

Palabras clave: narrativas, racionalidades, solidaridad, pragmatismo, neopragmatismo, imaginación.

\footnotetext{
Artículo presentado como resultado de investigación para el proyecto institucional INV-HUM 2359 titulado: "Narrativa, memoria y formación para la convivencia en el ámbito educativo universitario, fase 1", financiado por la Vicerrectoría de Investigaciones de la Universidad Militar Nueva Granada. DOl: http://dx.doi. org/10.15332/ s1794-3841.2018.0029.04

** Doctora en Filosofía. Docente de planta, Facultad de Educación y Humanidades, Universidad Militar Nueva Granada. Correo electrónico: martha.patino@unimilitar.edu.co. \# ORCID: http://orcid.org/0000-0002-1467-8889 Dirección postal: Cra. 11 №101-80, Bloque C, piso 3, Bogotá D. C., Colombia.
} 


\section{The imaginative narrative as a way of accessing solidarity. An educational proposal from pragmatism and neopragmatism}

\section{Abstract}

This article raises the need to acknowledge the forms of narrative present in educational processes, and also presents the need for taking into account another more subtle form and directed towards education of sensitivity for solidarity, as the main hypothesis of this text argues that individuals are educated in two particularly powerful ways of rationality, which derive in a desensitization towards others and towards nature. This particular situation is evidenced in radical selfishness, in unconscious consumerism, in the exclusion of others and in the destruction of nature. As a method of analysis, the problem is examined under the light of the criticism of objective-positive thinking, from the point of view of Dewey's classical pragmatism and Rorty's neopragmatism as well as the corresponding critique of technological-instrumental reason is presented from the Frankfurt School. All of the above in order to offer a proposal of a lexicon, that allows us to integrate an imaginative narrative that is oriented towards the creation of an ethos of empathy and solidarity, which is considered a utopian perspective, possible only to the extent that it makes visible another aspect of humanity ignored most of the time in educational environments, to make possible the moral progress that as humans constitutes our responsibility.

Keywords: narratives, rationalities, solidarity, pragmatism, neopragmatism, imagination

Received: November 24, 2016

Evaluated: February 23, 2016

Accepted: April 16, 2016 


\section{A narrativa imaginativa como forma de acesso à solidariedade. Uma proposta educacional do pragmatismo e do neopragmatismo}

Recebido: 24 de novembro de 2017

Avaliado: 23 de fevereiro de 2018 Aceito: 16 de abril de 2018

\section{Resumo}

Este artigo suscita a necessidade de reconhecer as formas de narrativa presentes nos processos educacionais, e suscita a necessidade de integração de um modo mais sutil e educativo de sensibilidade à solidariedade, uma vez que se baseia na hipótese que sustenta que os indivíduos são educados em duas formas particularmente poderosas de racionalidade, que derivam uma dessensibilização para com os outros e para com a natureza, evidenciada no egoísmo radical, no consumismo inconsciente, na exclusão de outros e na destruição da natureza. Como um método de análise, o problema à luz do objetivo positivo o pensamento crítico, a partir do pragmatismo clássico de Dewey e neopragmatismo de Rorty, assim como a crítica correspondente trata de razão instrumental-tecnológico é examinado a partir de a escola de Frankfurt. Tudo isso para oferecer uma proposta de léxico, uma narrativa imaginativa orientada para a criação de um ethos de empatia e solidariedade, que é considerado uma perspectiva utópica, só possível na medida em que tornar visível outra área do humano, para possibilitar o progresso moral que como humanidade constitui nossa responsabilidade.

Palavras-chave: narrativas, racionalidades, solidariedade, pragmatismo, neopragmatismo, imaginação. 
"La solidaridad humana no se logra mediante la investigación académica, sino a través de la capacidad imaginativa de ver a los demás como compañeros en el sufrimiento".

Richard Rorty

\section{INTRODUCCIÓN}

El ejercicio reflexivo que se trabaja en este texto propone que educar desde las racionalidades objetiva e instrumental, origina una subjetividad orientada a fines, competitiva, eficiente, productiva y ególatra. Esta subjetividad se hace efectiva en las interacciones sociales, las cuales derivan en sociedades en conflicto. Los sujetos no saben o no pueden sentir compasión por los demás o ser solidarios con los demás, puesto que han sido adiestrados para excluir, para luchar, para sobrevivir en un mundo aparentemente competitivo. Por tal razón, se plantea la necesidad de incluir una forma de pensar narrativa imaginativa que haga posible reconocer las experiencias de sufrimiento ajenas, y por ende, sentir el dolor del otro. Esto solo es factible en la medida en que se educa también para sentir, para oír, para reconocer la empatía, como una habilidad política que la educación se encuentra en mora de desarrollar, por cuanto al comprender la alteridad, se puede llegar a ser solidario, porque, en la medida en que nos autotrascendemos para dejar de escuchar el díalogo interno, de este modo se abre una vía de acceso al diálogo y a la solidaridad. Por ello, se escogen aquí a Dewey y a Rorty para plantear una articulación entre narrativa imaginativa y solidaridad, tanto en el pragmatismo clásico como en el neopragmatismo rortiano.
En un primer momento, se plantea una crítica a dos formas de racionalidad, dentro de las cuales se enmarca la educación hoy, a saber: la racionalidad objetiva y la racionalidad tecnológica, en sus presupuestos esenciales. Esta crítica se plantea a partir del pragmatismo de John Dewey y de la escuela de Frankfurt para mostrar que dichas aproximaciones a la racionalidad, no solo reducen lo real a un cúmulo de objetos, sino que además le dan a la naturaleza y al ser humano la categoría ontológica de útil. Esta forma de 'leer' tanto la realidad como al hombre, necesariamente convierte la educación en una maquinaria reproductora de esta forma de mirar y en consecuencia a los sujetos, en entidades aisladas y competitivas, lo que da como resultado sociedades fragmentadas incapaces de tolerancia, compasión e inhabilitadas para la convivencia. Así mismo, en un segundo momento, se ofrece, desde el planteamiento de la racionalidad narrativa de Rorty, una propuesta acerca de cómo desde el relato, desde las historias cotidianas, se posibilita la configuración de una comunidad inclinada a la solidaridad, a partir de entrar en contacto con el sufrimiento de los demás, porque la literatura y las historias de vida constituyen una vía de acceso a una mirada compasiva, de tal suerte que es posible ampliar el círculo de los que nos importan, hacia una comunidad cada vez más amplia. En este sentido, el texto presenta una mirada esperanzadora en relación con la función de la educación, por cuanto, en términos de Rorty, "la solidaridad no se descubre, sino se crea por medio de la reflexión" (Rorty, 1991, p. 18) y es en su tarea terapéutica y equilibradora, que la educación debe ocuparse de lo relevante, es decir, darle la misma importancia que le otorga al pensamiento objetivante e 
instrumentalizado, para empezar a formar en el ejercicio de la escucha en lugar del juicio, creando un ethos inclusivo y solidario.

Por último, se plantea, desde la articulación entre Dewey y Rorty, el reto en educación, puesto que esta tiene por delante la tarea de formar individuos hábiles para comprender e imaginar el sufrimiento del otro, en la medida en que se entiende a los demás, no como competidores a superar, sino "como compañeros en el sufrimiento" (Rorty, 1991), de manera que, a partir de lo posible, formar en una sensibilidad hacia la distinción entre la crueldad y la solidaridad. Esta tarea no es fácil, puesto que estos tres tipos de racionalidad se encuentran en tensión en los currículos, especialmente en la educación superior, de tal forma que en los procesos de formación se prepara al individuo profesionalmente para, desde la racionalidad positiva, medir y cuantificar, y desde la racionalidad instrumental-tecnológica, se lo entrena a ver el mundo tanto natural, como social, incluido él mismo como una fuente de recursos, en el cual el individuo es una máquina productiva y eficiente.

\section{Contexto}

La reflexión que se presenta aquí, como se ha señalado en la introducción, constituye una propuesta de educación desde lo estético en el sentido originario de aisthesis relacionada con los sentidos, con el sentir y con el dar sentido. Habida cuenta que, desde una perspectiva pragmatista, la narrativa se entiende como cualquier relato que se articule para comprender la realidad. En este sentido, Todo relato que haga esto, es una forma de narrar. Rorty (1991) explica que los tipos de racionalidad propios de la modernidad son realmente relatos que intentan dar sentido a lo real, por lo cual no son verdades inmutables, sino formas de narrar. Dentro de la categoría de narrativa se encuentran: el relato de la ciencia, desde una aparente objetividad, el relato de la técnica, desde una forma de narrar el mundo en términos instrumentales de eficiencia y productividad, pero además, se encuentra también la forma en que se narran los individuos en sus experiencias, en cómo sienten la vida, en cómo enfrentan las vicisitudes, en cómo se entienden frente al mundo desde su experiencia particular. Son estos últimos relatos, de acuerdo con Rorty, los que enriquecen la comprensión de la experiencia, porque muestran las diferentes aristas y sentidos. Estos se encuentran especialmente en la literatura, o en el relato que cada uno cuenta de sí mismo, de su propia historia. Este relato, siendo tan importante para construir un diálogo intersubjetivo, es el que lastimosamente se diluye en el sistema educativo, es el que por causa de la objetividad positiva y la eficiencia instrumental-tecnológica, es desplazado para ser pasado por alto. Recuperarlo sería una tarea de la educación de la sensibilidad humana, este es el planteamiento de Dewey, inspiración de Rorty en este aspecto.

En la medida en que el oficio de interpretar y pensar lo real consista en reconocer los rasgos propios de la época, como educadores nos corresponde evaluar y definir el camino que históricamente ha recorrido la humanidad, examinando la configuración del presente $y$, de alguna manera, prediciendo o imaginando el lugar al cual se llegará a partir de las condiciones del momento. Por tal motivo es urgente ocuparse de los asuntos humanos que configuran intersubjetivamente 
el mundo y en consecuencia, evaluar críticamente la relación entre el comportamiento humano, el uso de metodologías positivo-objetivas y tecnológicas, a fin de elaborar un registro de los aspectos estructurales relevantes de modo que sea posible suministrar los elementos necesarios para tomar decisiones en beneficio de dicha humanidad. Pero para ello, es preciso reconocer las texturas de lo real, las singularidades de la propia experiencia que derivaría en el reconocimiento del otro en sus particularidades, con sus interpretaciones 'sui generis'. Se requiere, además, que como sociedad podamos educar en la capacidad de escuchar la experiencia y el modo de significar propio y del otro. En este punto, se relacionan las propuestas de Dewey y de Rorty, puesto que mientras que el pragmatismo deweyano se centra en la experiencia, el neopragmatismo de Rorty lo hace en el lenguaje. Por lo tanto, a partir de estas dos aproximaciones, se podría plantear el modo de desarrollar la habilidad de la empatía desde el ámbito educativo, en la medida en que se forma con aquellos que no experimentan el mundo del mismo modo que nosotros. Sin embargo, significar o dar sentido no son procesos que ocurran desde una mirada objetiva; para Dewey,

[...] antes que significar [o dar sentido] sea tópico de verificación, sintaxis gramatical, estructura lógica o análisis categórico, es un asunto de historias, canciones de cuna, juegos, expresiones de sentimientos, interacción social, religión educación y arte. El lenguaje, en este sentido inclusivo es el medio por el cual los humanos participan de la cultura. Vivir una vida humana es vivir en un mundo permeado por significación y valor (Alexander, 1987, p. 120).
Y es que la época en que nos encontramos está signada por las paradojas, porque jamás había habido tanto desarrollo tecnológico y en las comunicaciones como en el presente; nunca antes en la historia de la humanidad habíamos estado tan interconectados de manera global, y sin embargo, nunca como ahora se ha evidenciado con tanta fuerza la crueldad entre personas, jamás como ahora hemos presenciado tanta incapacidad para aceptar las diferencias políticas, culturales, raciales, de género, religiosas, etc. En este sentido, se considera de suma urgencia contribuir en el desarrollo de la habilidad para la apertura y la comprensión, pero la comprensión que se requiere hoy demanda un giro de lo objetivo-positivo e instrumental a la sensibilidad compasiva y empática, puesto que nuestro modo de comprender y dar sentido, en la medida en que es objetivante e instrumentalizado, al fragmentar, matematizar, medir y utilizar el mundo, lo reduce a elementos manejables, lo simplifica reduciendo a los seres humanos también a mecanismos productivos y ególatras. Por lo tanto, en un mundo global e interconectado, estamos llamados a replantear la episteme que subyace a la interpretación y a recomponerla con elementos poéticos, estéticos y creativos, que en realidad interconecten a los individuos. Debemos educar seres humanos capaces de esa conexión de comprensión y simpatía, individuos libres para exponer sus relatos, ampliarlos, enriquecerlos con los de otros y de ser respetados en su experiencia vital.

Con el fin de realizar una reflexión situada, tanto en el contexto histórico como local, se plantean las coordenadas desde las cuales se pueda pensar el problema de la función de la narrativa en el modo de dar sentido a 
la realidad. Se trata de poner en perspectiva las descripciones vigentes de lo real para incluir otras formas de narrativa, otros léxicos que integran aspectos de lo humano, que han sido desestimados. Estas descripciones provienen de distintas formas de racionalidad, a saber: 1) racionalidad objetiva, 2) racionalidad instrumental-tecnológica y, 3) racionalidad narrativa-imaginativa. Cada una de estas tres maneras emerge de una cierta forma de significar y comprender la realidad, con su correspondiente relación con la verdad y que por supuesto, derivan en un ethos específico. En ese sentido, existen modos de comprender que exceden los límites de la convención. Dentro de las comprensiones convencionales encontramos aquellas que narran el mundo en términos descriptivos, tal es el caso de la ciencia; otras narrativas que lo narran en términos operativos, desde la razón instrumental-tecnológica y otras, ya no convencionales o aceptadas, que se configuran desde una comprensión de la contingencia, del sentimiento y de lo cotidiano, como ocurre con la poesía, la literatura o con el relato de cada uno de nosotros, el cual da sentido a nuestras vidas.

Señala Rorty (1991) que es necesario aprender a distinguir entre los relatos que influyen en la construcción de nuestra autonomía y otro tipo de relatos que contribuyen a debilitar nuestra crueldad. Para él, aquellos que estimulan la imaginación y efectúan una influencia sobre nuestras acciones y sentimientos, son los que nos impulsan a ser autónomos, y los otros, nos hacen conscientes sobre los efectos que nuestras acciones puedan llegar a tener en otras personas, ayudándonos a articular el sentimiento individual con lo que Rorty llama una utopía esperanzadora, una política cosmopolita. Estos relatos, como novelas, cuentos, historias de vida o informes etnográficos, contribuyen al progreso moral de la humanidad, porque al describir de manera detallada las variedades del dolor y la humillación humanas, permiten el reconocimiento e identificación con el otro desde los sentimientos de solidaridad y empatía. Esto a diferencia de los relatos que se proclaman objetivos y verdaderos, como los tratados filosóficos, o los estudios científicos o religiosos, por cuanto estos relatos diluyen el sentimiento, privilegian la frialdad y separación aséptica a partir del ideal de una objetividad soberana y fomentan un ethos de exclusión, de consumismo y de egoísmo.

Según nuestra perspectiva, siguiendo a Clarissa Pinkola (1998), los relatos enferman o son medicina; enferman aquellos que inoculan la semilla de la separación, la desconfianza y la negatividad, son medicina cuando tienen el poder terapéutico de reparar, de cultivar el sentimiento de pertenecer al cosmos y de ser parte de una comunidad humana, mediante la simpatía, son medicina cuando engendran emoción, tristeza, preguntas, cuando amplían la imagen del mundo, cuando evocan pulsiones perdidas y cuando reparan la sutil conexión con el otro. Son medicina cuando:

[...] tocan el nervio auditivo que discurre por la base del cráneo y penetran en la médula oblonga, justo por debajo del puente de Varolio. Allí los impulsos auditivos se transmiten a la consciencia o bien al alma, según sea la actitud del oyente. Los antiguos anatomistas decían que el nervio auditivo se dividía en tres o más caminos en el interior del 
cerebro. De ello deducían que el oído podía escuchar a tres niveles distintos. Un camino estaba destinado a las conversaciones mundanas. El segundo era para adquirir erudición y apreciar el arte y el tercero permitía que el alma oyera consejos que pudieran servirle de guía y adquiriera sabiduría durante su permanencia en la tierra. Hay que escuchar por tanto con el oído del alma, pues esta es la misión del cuento (p. 34).

Por tanto, en el espíritu de esta apertura a la escucha, es que se aborda el problema en este texto.

Desde hace un tiempo nos han interpelado preguntas acerca de cómo formar individuos capaces de cultivar el sentido de escucha, capaces de una sensibilidad tal que puedan reconocer el sentimiento de pertenecer a una comunidad humana muy amplia y, sobre todo, aquella de cómo formar con un sentido de solidaridad en una cultura que privilegia el egoísmo, la competitividad, la crueldad y la discriminación.

Cuando se hacen preguntas de esta índole, se está dando por sentado que el sentido de la solidaridad en nuestro mundo escasea notablemente y que aquello que prolifera es la crueldad y la discriminación, y es que siguiendo a Dewey, Rorty (en Contingencia ironía y solidaridad, 1991) advierte que la objetividad alcanzada mediante el entrenamiento académico y en consecuencia la teoría sobre la realidad, no conducen a la solidaridad; que para lograr acceder a ella es necesario el empleo de la imaginación, la cual pone en juego el sentimiento de entender a los demás como compañeros en el sufrimiento. En ese sentido, la solidaridad no es un concepto, es un sentimiento que se educa y fortalece cuando aprendemos a identificarnos con el otro. Pero esa solidaridad no consiste en la identificación de un yo medular en todos los seres humanos, expresado en un ámbito trascedental como la racionalidad o la objetividad, sino, según afirma Rorty, en "la capacidad de percibir cada vez con mayor claridad que las diferencias tradicionales de tribu, de religión, de raza, de costumbres, carecen de importancia cuando se las compara con las similitudes referentes al dolor y la humillación" (1991, p. 209). Por lo tanto, la solidaridad constituye una aptitud para tener en cuenta dentro del círculo de los que importan a personas completamente diferentes. Este círculo debe ser ampliado cada vez más a fin de lograr evolucionar moralmente como humanidad. Eso significa que lo que nos espera desde la educación, es poder formar individuos capaces de establecer la diferencia entre la crueldad y la solidaridad, capaces de extrapolar el sentimiento de empatía a grupos cada vez más grandes hasta llegar a la totalidad de la humanidad, especialmente teniendo en cuenta, señala Rorty, las similitudes con aquellos que sufren, con los marginados, los cuales son personas que instintivamente concebimos como si estuvieran del otro lado. Sin embargo, y allí está el valor de la narración de la vida del otro, porque cuando otro narra su dolor, directamente o a través de un narrador, es posible ponernos en su lugar e identificarnos mediante la imaginación y la sensibilidad.

Así, no es extraño que hoy estemos pensando en cultivar la solidaridad, por cuanto se ha venido afirmando el valor del individualismo mediante dinámicas epistémicas y económicas que lo fomentan, a la vez que 
estimulan la exclusión de grupos, al interior de los países, que alimentan el conflicto entre naciones y promueven la destrucción de la naturaleza. En pocas palabras, el modo como estamos educando promueve un 'crecimiento insostenible' en contra del exaltado 'desarrollo sostenible'.

Pensar la educación, en este artículo, consiste en reflexionar desde una mirada que Rorty denomina 'utópica', en diálogo con formas de narrar y significar, desde territorios cuya particularidad se construye desde las identidades, pero particularmente desde lo común, de modo que se pueda pensar en la construcción de una cultura de paz, particularmente porque en el contexto histórico de Colombia, se requiere la reflexión en este sentido.

Desde esta perspectiva entonces, se considera que somos introducidos a un mundo arbitrariamente impuesto gracias a otros, y como humanos, nos corresponde aprender a reconocer aquello compartido, desde lo propio de las identidades, especialmente en un país con tan diversas etnias, creencias y convicciones de toda índole. Por ello, el acento de una cultura de paz, tiene como horizonte entender la relación de reconocimiento de las diferencias y semejanzas, lo que no es posible sin la natural consideración de lenguajes, de léxicos -en sentido rortiano- y epistemes que dialogan de manera que configuran una realidad compuesta por diversidades. Pero a este reconocimiento de la diversidad no se puede arribar si no se entiende que el otro es un otro que sufre y siente. En este sentido, se propone que la función de la educación es de vital importancia, porque de lo que se trata es de la educación de la sensibilidad, esto es: del desarrollo de habilidades emotivas desde la narrativa de las experiencias particulares, desde los relatos de sufrimiento que conmueven. Por ello, los relatos en la literatura y en el arte constituyen una vía de acceso a este ideal utópico y al progreso moral de los pueblos. La apertura hacia un nosotros más inclusivo, según Rorty, que continúe

\section{[...] extrapolando en la dirección a la} que llevaron determinados acontecimientos del pasado: la inclusión entre "nosotros" de la familia de la caverna de al lado, después la de la tribu del otro lado del río, después, la de la confederación de tribus del otro lado de la montaña, más tarde la de los infieles del otro lado del mar [...]. Es ese un proceso que debiéramos intentar que prosiguiese. Debiéramos tener en la mira a los marginados: personas que instintivamente concebimos aún como “ellos" y no como "nosotros". Debiéramos intentar advertir nuestras similitudes con ellos..., proponernos crear un sentimiento de solidaridad más amplio que el que tenemos ahora (1991, p. 214).

Para que sea posible la propuesta rortiana, es necesario el acceso a otra manera de racionalidad que se ubique en el ámbito del sentir. El presente texto, entonces, explicita las formas de racionalidad presentes $y$ el modo como cada una de ellas se orienta hacia una finalidad distinta, esto es: formar un cierto tipo de subjetividad. No obstante, la subjetividad a la que se hace referencia no es la subjetividad de la racionalidad moderna, sino otro tipo de subjetividad: la de la experiencia particular de los individuos. Con el fin de mostrar estos momentos, la investigación se apoya en el pensamiento 
pragmatista clásico de Dewey, en la escuela de Frankfurt y en el neopragmatismo de Rorty. Cada una de estas perspectivas es útil, bien sea para la elaboración de la crítica, como para la presentación de la propuesta en cuestión.

Es así como se parte desde la caracterización de la racionalidad como un rasgo que todos los seres humanos compartimos. Sin embargo, sabemos que la razón no es la única cualidad exclusiva del ser humano; por ejemplo, Hospers señala que le es propio al hombre, el sentido moral o de la angustia; Bergson, nos dice que el rasgo peculiar del ser humano es la risa, o la sevicia puesto que "el hombre es el único animal que realiza asesinatos con un hacha... y el que guarda durante años su odio mientras va planeando la manera de vengarse de su enemigo..." (Hospers, 1979, p. 124). Se ha escogido, nos dice Rorty, a la razón arbitrariamente como aquel ámbito fundante, común y distintivo del ser humano, sencillamente como un elemento útil que permite elaborar un modelo organizado jerárquico y más reconocible con el fin de separarlo de todo lo demás.

\section{RACIONALIDAD OBJETIVA}

La objetividad de la razón se puede reconocer en tres importantes aspectos, a saber: el modelo dualista, la subjetividad objetiva y su relación con un mundo objeto, y por último, la configuración de una forma de subjetividad.

\section{Modelo dualista}

La racionalidad objetiva es un tipo de racionalidad arrogante que desprecia la contingencia y ama lo estable; esta adquiere su rasgo de objetividad, en virtud de un modelo dualista que permite separar dos realidades, una de las cuales fundamenta la otra, merced a su importancia ontológica. Esta crítica es la base del pensamiento de John Dewey, quien señala que en la tradición occidental ha habido distintas formas de dualismo ontológico, el cual se puede rastrear desde Pitágoras, quien opone el límite y lo ilimitado, pasando por Platón, quien formula la existencia de un mundo sensible y otro inteligible, recogiendo a los atomistas quienes separan el vacío de la multiplicidad, o en la obra de Descartes, quien establece la separación entre espíritu y materia, o Kant, quien divide la razón práctica de la moral, e incluso los espiritualistas que formulan la separación entre naturaleza y espíritu. Todos estos dualismos han tenido como meta la de establecer la separación entre lo externo-lo interno, sujeto-objeto, lo físico-lo síquico, lo real-lo ideal, lo inmanente y lo trascendente, para conformar una visión de realidad, de suerte que lo real tiene más validez ontológica, por corresponder esta realidad con lo estable, lo inmutable y lo eterno. Dewey rechaza la naturaleza ontológica ${ }^{3}$ de estas descripciones, ya que al intentar establecer una jerarquización, configuran un modelo que se funda en axiomas metafísicos, los cuales permiten hablar de objetividad. Esta representación de lo real, se ha denominado objetiva, y la tarea del conocimiento consiste en cartografiar fielmente el "territorio", el cual puede

3 La crítica de Dewey a los distintos dualismos se puede encontrar: sobre el dualismo cuerpo-alma (Dewey, LW10, pp. 26-28); sobre el dualismo material-ideal (Dewey, LW10, pp. 34, 38, 108 y 109); para pensamiento-sensación (Dewey, LW10, pp. 125, 161, 251-2 y 263); forma-sustancia (Dewey, LW10, pp. 111-138); para hombre-naturaleza (Dewey, LW10, pp. 152-155, 163, 190, 336 y 341); para yo-mundo (Dewey, LW 10, pp. 109, 252, 254, 274-5 y 286); para sujeto-objeto (Dewey, LW10, pp. 251, 281 y 292) y para medios-fines (Dewey, LW 10, pp. 201-202). 
reducirse a cantidades desprovistas de cualidades, principios, o criterios ya hechos " $r e$ ady-made", donde el cartógrafo observa el territorio desde fuera. Esta visión convierte el mundo en un mundo sin profundidad, en un conglomerado de cosas y datos.

Este relato dominante proporciona una visión "comprensible" que permite clasificar, ordenar y separar, a tal punto que se constituye un mundo dual en el que un sujeto racional, dividido en res extensae y res cogitans, se entiende con un mundo objeto sin mayores contrastes. Esta mirada enfatiza la

\section{[...] aceptación de conceptos unívo-} cos taxativos y a la eliminación de los analógicos, de tal forma que el sujeto aparece escindido, por un lado, como res extensa sometido al espacio y al tiempo y por otro, la res cogitans o autoconsciencia por fuera del espacio y del tiempo (Del Bravo, 2000, p. 18).

Por ello, la realidad se describe a partir de un modelo disyuntivo y exacto que niega la existencia de una naturaleza contingente, negando a su vez su carácter inestable que es la causa de toda dinámica creativa que surge de ella. Basta decir en este escrito que las consecuencias epistemológicas de esta configuración del mundo, derivan en una invisibilización de los individuos como seres con experiencias particulares y de los pueblos como intérpretes de la realidad, de tal modo que "se configura la institucionalidad" (De Sousa, 2014, p. 9) y se establecen sistemas políticos, económicos, educativos $\mathrm{y}$ éticos.

\section{La 'subjetividad objetiva' en el pensar representacional y de la relación con el mundo 'objeto'}

A partir de este rasgo aparentemente objetivo, se configura todo el modelo filosófico y científico de Occidente, el cual describe el mundo en sus categorizaciones fundamentales como una realidad física, que según Bertalanffy (2007), “es descompuesta en puntos de masa o átomos y el organismo vivo en células, el comportamiento en reflejos y la percepción en sensaciones puntuales". Este modelo se refiere al hombre solo como sujeto de conocimiento, separado del mundo, y quien otorga el sentido; de acuerdo con Hottois (1991), esta configuración obliga "a romper con nuestro ser-natural-en-el-mundo. Y esta ruptura priva al mundo de significado a la vez que hace de él un campo de operación y de acción" (p. 15). En este sentido, la subjetividad entendida desde la objetividad racional y soberana engendrada en la modernidad, se plantea como axioma del pensar representacional. La singularidad particular de este tipo subjetividad-objetiva, en este modelo, consiste en que el fundamento del conocimiento es un sujeto trascendental, en la medida en que este define la norma y la medida del sentido, del conocer, del ser y de la realidad; siguiendo a Heidegger, la subjetividad se define merced a un subyacente a toda representación como sustrato del conocer. Por ello, imaginar y sentir, no caben dentro de este modelo de representación, porque estas dos características corresponden a la vivencia individual.

Por lo anterior, la representación de la realidad a partir de este tipo de racionalidad, exhibe sus lenguajes, imperativos y 
mecanismos interpretativos que derivan en una particular versión de mundo, de hombre y de las relaciones implicadas. El relato que se entiende con un mundo estático y pasivo, reduce la realidad a elementos manejables, lo simplifica para poder controlarlo. Este modelo entiende al sujeto como un sujeto trascendental con una facultad para conocer las cosas tal como son para una consciencia cognoscente, la cual refleja la realidad 'tal como es'. La objetividad y validez del conocimiento se establecen merced a la naturaleza de esta autoconsciencia, su lenguaje es el matemático, garante de objetividad y su validación lógica garantiza la corrección y la verdad.

Esta narrativa entiende el conocimiento como una facultad de "ver" por un lado, aquello que es común en las cosas más insólitamente distintas y por el otro, en su modelo constituido por partes regidas por leyes causales inexorables, se adivina el orden causal de todas las cosas donde el cambio es un error y concentrarse en él demuestra la incapacidad de ir más allá, de reconocer patrones, puesto que conocer no tiene que ver con observar. Dewey señala que, para este relato del mundo, el verdadero conocimiento consiste en aprehender un fin definitivo que se mantiene dentro de los límites de la verdad inmutable. En ese sentido "la ciencia se ve constreñida al dirigirse hacia las realidades que subyacen detrás y más allá de los procesos de la naturaleza y a llevar adelante la búsqueda de estas realidades por medio de formas racionales que trascienden a los modos ordinarios de percepción e inferencia" (Dewey, MW 10, p. 11).

En este escenario, la mirada sobre la realidad implica un sistema de relaciones entre fenómenos y juicios, cuya naturaleza es la de servir de causa lógica para establecer nuevos juicios, de modo que se conforma un cuerpo de conocimiento donde cada juicio es verificado y probado. Por tanto, "científico" aquí significa "métodos regulares de controlar la formación de juicios relativos a algún objeto" (Dewey, LW 1, p. 15). Esta narración, en virtud de la vehemente búsqueda de exactitud y univocidad, se configura como un modo seguro de explicación a partir de la representación objetivada de la realidad, la cual se despliega en torno a grandes utopías engendradas en el cartesianismo analítico, el ideal baconiano del control y en la universalización kantiana de la racionalidad.

\section{La racionalidad objetiva y la configuración de una forma de subjetividad}

De manera muy resumida, es así como se configura un esquema donde el sujeto y el objeto se separan conformando una visión de la naturaleza sujeta a determinaciones y comprendida por la inteligencia humana, que se halla por fuera de dichas determinaciones merced a su libertad. Este tipo de metáfora, interpreta la naturaleza desde un método reduccionista, desde el cual se excluye la existencia y experiencia cotidiana de los individuos por considerarse inútil en un mundo donde los seres humanos desean por naturaleza conocer, medir y cuantificar.

Este relato de la objetividad opera, según Rorty, como modo de distanciarse de las personas reales que nos rodean, porque obliga a no concebirse a uno mismo como miembro de un grupo real o imaginario, sino más bien, vinculándose a algo que puede describirse sin referencias a seres humanos 
o realidades particulares; este es el más claro ejemplo del intento de encontrar sentido a la existencia abandonando la comunidad en pos de la objetividad. En este relato, por lo tanto la idea de la verdad como algo a alcanzar por sí misma y no porque sea bueno para uno o para la propia comunidad real o imaginaria, es el tema central de la tradición occidental. Al respecto, escribe Rorty (2000) que: "Somos herederos de una tradición objetivista centrada bajo el supuesto de que debemos saltar fuera de nuestra comunidad lo suficientemente lejos para examinarla a la luz de algo que vaya más allá de ella..." (p. 40) y, en tanto que pragmatista, juzga necesario "reducir la objetividad a la solidaridad", sin necesidad de recurrir a la metafísica, ni a una ontología, ni a una epistemología que valide o fundamente su objetivo, puesto que es necesario reconstruir la noción de verdad, pues para él es, siguiendo a James, "aquello en que nos es bueno creer" (p. 41 ), no porque la creencia tenga un referente objetivo que le otorgue un cierto peso fundante, ni porque esa objetividad remita a "un tipo de racionalidad natural y transcultural, que puede utilizarse para criticar a determinadas culturas y elogiar otras, sino simplemente como el bien real y el posible mejor" (p. 41), porque es necesario para la humanidad tener la posibilidad de ampliar el círculo de aquellos a quienes tenemos en cuenta, es preciso imaginar una humanidad que supere las fronteras de la identidad tribal, para lograr lo que él llama "un consenso intersubjetivo tan amplio como sea posible" (p. 41).

Esta manera de pensar heredada de la necesidad de encontrar un fundamento metafísico y ontológico que valide el presupuesto de la racionalidad en cuestión, ha derivado claramente en la forma como nos miramos a nosotros mismos, a la naturaleza, al cosmos, y por consiguiente, ha determinado la correspondiente relación, porque creemos que todas las cosas y las personas operan en un ámbito de separación, del mismo modo que estamos convencidos de que las acciones son el resultado de voluntades individuales o 'yoes' aislados y solo tienen consecuencias en nosotros como individuos. He ahí el rasgo fragmentario de este relato. De tal modo que entender el mundo como separado en unidades individuales, nos lleva al desgarramiento y a la desesperación, produciendo 'psicópatas', que en palabras de Rorty (2000), son “individuos cuya concepción de sí mismos no incluye consideración alguna de los demás" (p. 208). Esta es una de las consecuencias del pensamiento objetivo en términos sociales, puesto que educar en este pensamiento como única forma de interpretar la realidad, constituye una narrativa incompleta, que deriva en la configuración de sujetos sin capacidad para entenderse como parte de la humanidad.

\section{RACIONALIDAD INSTRUMENTAL O EL IMPERATIVO TECNOLÓGICO}

\section{El significado de 'racional' desde la instrumentalidad tecnológica}

Este tipo de racionalidad, es un modo de ser de la razón, que se valida por el efecto evidente que tiene en el mundo concreto, donde la utilidad y la productividad están a la orden del día. Jacques Ellul (2003), filósofo de la tecnología, establece que,

[...] la técnica, efectivamente, ha tenido su punto de partida en la existencia de la máquina. Es cierto que partiendo 
de la mecánica se ha desarrollado todo lo demás; como lo es también que sin la máquina no existiría el mundo de la técnica (p. 7).

No obstante, y aunque su origen sea la máquina, la técnica se ha independizado por completo de la máquina, pasando a constituir "la totalidad de las actividades del hombre $[\ldots]$ " (p. 8), porque el objetivo en el pensamiento técnico es el de "tranformar en máquina todo aquello que todavía no lo es" (p. 8), porque la técnica "[...] ordena y racionaliza [...] es eficaz y lleva a todas partes la ley de la eficacia" (p. 9), por consiguiente, según Ellul, la autonomía de la técnica, radica en que, al penetrar en todos los ámbitos, penetra incluso en el hombre mismo, lo convierte en objeto y paulatinamente lo absorbe, transformándolo en un ser mecánico.

El resultado de la mecanización converge con las estructuras económicas vigentes y se institucionaliza mediante la educación escolar o mediante los medios, invadiendo todos los ámbitos de la existencia humana. Todas las acciones dentro de este tipo de lógica están encaminadas al uso económicamente productivo del tiempo. En este sentido, toda actividad humana y con ella, toda significación de la existencia, se somete al modo de producción vigente, mediante la validación de la productividad y la eficiencia, las cuales justifican el trabajo, que así mismo se traduce en resultados en un corto tiempo con el menor costo posible. Todo hacer, en esta lógica, está encaminado a la obtención de este tipo de resultado.

Por estas razones, la racionalidad tecnológica orbita en el relato de la eficiencia, según el cual, ser eficiente consiste en aumentar la productividad, reproducir el sistema al costo que sea para poder garantizar los objetivos. Este proceso tiene lugar en un contexto histórico, donde intervienen intereses de índole económica, los cuales se racionalizan a partir del diseño y legitimación de procedimientos encaminados al dominio de la sociedad, como lo presagiara Marcuse (1993), porque la productividad es un relato -impuesto a los individuos-, "que destruye el libre desarrollo de las necesidades y facultades humanas" (p. 20) y enfrenta al hombre con la naturaleza. Esta nueva forma de racionalidad, según Marcuse, determina el desarrollo social por completo en virtud de su impronta tecnológica que transforma todo en un útil, por eso señala que:

En tanto que universo tecnológico, la sociedad industrial avanzada es un universo político, es la última etapa en la realización de un proyecto histórico específico, esto es, la experimentación, transformación y organización de la naturaleza [y al propio individuo] como simple material de dominación (p. 26).

Este dominio ha tenido lugar por vía de la educación, pues ya a comienzos del siglo XX,

[...] se abrieron áreas -como la psicología industrial, jurídica, organización del trabajo, administración, gestión-, que se desarrollaron como instrumentos tecnológicos de control del proceso global de producción. Parecía que las posibilidades de lo tecnológico podían ser casi ilimitadas y que los grandes problemas sociales se resolverían por vía técnica. Solo lo susceptible de ser tratado de forma numérica en términos de valores discretos puede definirse como problema, lo demás tendrá el carácter de pseudoproblema (Brum, 2010, p. 3). 
En esta misma perspectiva, comenta Brum que "los grandes centros de poder se imponen a la sociedad para que su acción se ajuste a concepciones que obedezcan a sus intereses" (p. 15).

Vale decir con Castells (2001) que,

[...] el poder ya no se concentra en las instituciones (el Estado), las organizaciones (empresas capitalistas) o los controladores simbólicos (empresas mediáticas, Iglesias), se difunde en redes globales de riqueza, poder, información e imágenes que circulan y se transmutan en un sistema de geometría variable y geografía desmaterializada (p. 398).

Este nuevo poder reside en un aspecto más delicado e intangible, en un ámbito simbólico que anida en narraciones y metáforas asociadas con,

[...] los códigos de información y en las imagines de representación en torno a los cuales las sociedades organizan sus instituciones y la gente construye sus vidas y decide su conducta, la sede de este poder es la mente de la gente (p. 399).

La crítica de Weber (2002) a la racionaldiad instrumental, se centra en el problema de la dominación ${ }^{4}$ y la manipulación tanto de la naturaleza externa como de la interna

4 Sobre el término dominación, comenta Weber (2002): "Debe entenderse por 'dominación', [...] la probabilidad de encontrar obediencia dentro de un grupo determinado para mandatos específicos (o para toda clase de mandatos). No es, por tanto, toda especie de probabilidad de ejercer 'poder' o 'influjo' sobre otros hombres. En el caso concreto esta dominación ('autoridad'), en el sentido indicado, puede descansar en los más diversos motivos de sumisión; desde la habituación inconsciente hasta lo que son consideraciones puramente racionales con arreglo a fines. Un determinado mínimo de voluntad individual. Este imperativo de dominación deriva en una distorsión de la realidad y, en consecuencia, del modo como se actúa en ella, por cuanto presenta a la naturaleza y al ser humano como degradados a simple materia, cosas para ser dominados.

Hoy más que nunca, se hace manifiesto y real lo que apocalípticamente anunciara ya Heidegger en el pasado siglo, cuando afirmó que el verdadero problema con la técnica y el patrón racional que se asocia a ella, reside en que el hombre se considera a sí mismo como un mecanismo, una cosa y un recurso, razón por la cual no le es posible tener acceso a una verdad más originaria, engendrándose en él una condición de desarraigo que lo lanza hacia una existencia inauténtica, la cual se evidencia en el tipo de relación que plantea con los otros y con la naturaleza. Este modo de comprenderse constituye en sí mismo un peligro, por cuanto la técnica moderna se erige desde una pretensión totalizadora y abarcante y su impronta se convierte en criterio único de descripción y sentido de la realidad en todos sus ámbitos, puesto que, de acuerdo con Heidegger en su ensayo: “La pregunta por la técnica" (1997), el cual aparece en el texto Filosofía, ciencia y técnica, establece que la técnica configura un mundo en el cual no hay valor aparte del uso, donde la tecnología no es un conjunto de artefactos, sino más bien, un tipo de pensamiento que manipula consume y descarta. Según su parecer, el pensamiento tecnológico constituye una estructura epistémica y ontológica, desde la cual no se busca la comprensión, tan solo usar, o quizá su comprensión y léxico propio son los de el uso y el descarte. Esta racionalidad es el

de obediencia, o sea de interés (extemo o interno) en obedecer, es esencial en toda relación auténtica de autoridad" (p. 170). 
modo como educamos profesionales en las universidades, de manera que la excelencia y calidad se ven afectadas por el imperativo instrumental-tecnológico.

En este escenario, por lo tanto, "racionalizar significa: "ser más eficiente, aumentar la productividad, reproducir y expandir los mejores métodos o técnicas para un máximo rendimiento y controlar el proceso global de producción" (Brum, 2010, p. 5). A partir de este paradigma, como lo señalara Heidegger (1994, pp. 25 y 30), la naturaleza queda reducida a un stock de energía, en tanto que el hombre y las cosas, quedan reducidos a un recurso. En este modo de entender la racionalización, lo que no es útil, en el sentido de eficacia, que implique ganancia, queda descartado y lo que se ajusta a este criterio, funciona muy bien: el recurso humano, el recurso natural, etc. Funcionar bien implica reproducir el sistema al costo que sea y llevar a cabo los fines de sectores de poder bien demarcados. En este orden de ideas, racionalizar consiste en el empleo de técnicas que justifiquen un modo de pensar totalizante, de tal forma que se convierte en el único referente epistemológico válido. Cuando este tipo de "razón" se identifica con la utilidad $\mathrm{y}$, por ende, aplica su lógica a todo lo real, obliga a la realidad a obedecer a un patrón lógico proveniente de una voluntad de control y manipulación. Lo que en últimas se busca es un universo completamente racionalizado en estos términos.

Horkheimer (2002) critica este tipo de racionalidad, al afirmar que,

[...] en su aspecto instrumental, tal como lo destaca el pragmatismo, se ve acentuada su capitulación ante contenidos heterónomos. La razón aparece totalmente sujeta al proceso social. $\mathrm{Su}$ valor operativo, el papel que desempeña en el dominio sobre los hombres y la naturaleza, ha sido convertido en criterio exclusivo (p. 32).

Es merced a este criterio exclusivo que se validan el conocimiento, las ideas y el sentido, todo orientado a fines:

Cuanto más automáticas y cuanto más instrumentalizadas se vuelven las ideas, tanto menos descubre uno en ellas la subsistencia de pensamientos con sentido propio. Se las tiene por cosas, por máquinas. El lenguaje, en el gigantesco aparato de producción de la sociedad moderna, se redujo a un instrumento entre otros. Toda frase que no constituye el equivalente de una operación dentro de ese aparato, se presenta ante el profano tan desprovista de significado como efectivamente debe serlo de acuerdo con los semánticos contemporáneos, según los cuales es la frase puramente simbólica y operacional, vale decir enteramente desprovista de sentido, la que denota un sentido. La significación aparece desplazada por la función o el efecto que tienen en el mundo las cosas y los sucesos. Las palabras, en la medida en que no se utilizan de un modo evidente con el fin de valorar probabilidades técnicamente relevantes o al servicio de otros fines prácticos, entre los que debe incluirse hasta el recreo, corren el peligro de hacerse sospechosas de ser pura cháchara, pues la verdad no es un fin en sí misma (p. 33).

Es en este escenario sombrío, en el cual la educación opera como legitimadora de estas 
dinámicas, que la investigación se convierte en mecanismo generador de productividad. Según afirma Bordieu (2003), la ciencia y la investigación se han convertido en subsidiarias de procesos ajenos a ellas y han pasado de ser un oficio de comprensión a convertirse en tareas instrumentales que sirven a claros intereses: haciéndose realidad la sentencia heideggeriana sobre el pensamiento calculante, según la cual, la racionalidad humana se ha reducido a calcular y medir y ha dejado de lado el pensar meditativo:

La autonomía que la ciencia había conquistado poco a poco frente a los poderes religiosos, políticos, o incluso económicos y parcialmente a las burocracias estatales que garantizaban las condiciones mínimas de su independencia, se ha debilitado considerablemente. Los mecanismos sociales que iban apareciendo a medida que dicha autonomía se afirmaba, como la lógica de la competitividad entre los iguales, corren riesgos de ser utilizados en provecho de objetivos impuestos desde fuera. La sumisión a los intereses económicos y a las seducciones mediáticas amenaza con unirse a las críticas externas y a los vituperios internos, cuya última manifestación son algunos delirios "posmodernos" para deteriorar la confianza en la ciencia, y muy especialmente, en la ciencia social... En consecuencia, la ciencia está en peligro y se vuelve peligrosa (p. 7).

\section{La domesticación desde lo tecnológico}

De igual manera, Marcuse, como se ha dicho, y Habermas, señalan que el problema de la racionalidad tecnológica no consiste tanto en que haya intención de dominación y control hacia los individuos, sino, lo que es más grave, que los individuos acceden gustosamente, merced al engaño de la satisfacción y el bienestar. Por su parte, Marcuse sostiene que la racionalidad tecnológica, despoja al ser humano de su individualidad, motivándolo a permanecer en un estado de domesticación y conformidad merced a las necesidades artificiales que habrá de satisfacer, negándole la posibilidad de crítica o rebeldía, convirtiéndolo en incapaz de autonomía. Desde esta perspectiva, el hombre habita el mundo en su unidimensionalidad.

La tecnología se ha convertido en el gran vehículo de la reificación: la reificación en su forma más madura y efectiva. La posición social del individuo y su relación con los demás parece estar determinada no solo por cualidades y leyes objetivas, sino que estas cualidades y leyes parecen perder su carácter misterioso e incontrolable; aparecen como manifestaciones calculables de la racionalidad (Marcuse, 1993, p. 196).

Por su parte, Habermas reconoce que la progresiva racionalización de la sociedad tiene su origen en la institucionalización del progreso científico y técnico, donde la técnica es ideología en la medida en que enmascara las dinámicas de dominio y control social, merced al vínculo con el crecimiento económico dentro del sistema capitalista de producción. El engaño radica en la creación de lealtades a cambio de un supuesto bienestar, lo que arrastra a las personas al conformismo, rasgo fundamental para generar el incremento en el ingreso económico; se trata de implantar un tipo de acción racional que es en sí mismo una forma de control. Debido a esta penetración de la ciencia 
y la técnica, se validan e institucionalizan nuevas formas de entender la acción, cuya impronta es su instrumentalización de cara al control de lo material. Este tipo de racionalidad "proporciona la gran legitimación a un poder político expansivo que engulle todos los ámbitos de la cultura" (Habermas, 1986, p. 58), la cual invade incluso los espacios esenciales de la libertad humana, con la falsa promesa de liberar al hombre del dominio del trabajo, lo somete aún más, no por que la ciencia y la técnica permitan el dominio, sino porque el propio pensamiento científico-técnico, en sí mismo, es ya un pensamiento dominador desde el cual el dominio de la naturaleza, dada la naturaleza de este pensamiento, deriva en un dominio del propio hombre (p. 60), pues se trata de implantar un tipo de acción racional que es de por sí una forma de control.

\section{LA NARRATIVA IMAGINATIVA PRAGMÁTICA: UNA VÍA DE ACCESO HACIA LA SOLIDARIDAD}

Entiéndase por narrativa una forma de acceso a la realidad a partir de relatos y narraciones. Dentro de la categoría de los grandes relatos está el relato de la objetividad o el relato de la instrumentalidad. Rorty señala que todas las explicaciones de lo real son narrativas a partir de un léxico histórico, contextual, situado en una geografía y merced a dinámicas sociales específicas, pero que tienen consecuencias sobre el modo como nos decimos, nos relatamos, nos simbolizamos y nos entendemos como individuos. Así mismo, plantea, inspirado en la obra de Dewey, que existen otros relatos como los literarios, que pueden llegar a convertirse en una vía de acceso a la solidaridad, merced a la exploración que hacen de lo afectivo y lo emocional. La narrativa imaginativa penetra en el

[...] relato de los sujetos. Estos relatos que la gente cuenta sobre la vida personal o docente hablan de lo que hacen, sintieron, les sucedió o las consecuencias que ha tenido una acción, siempre contextualmente situados en relación con otros; no desde un yo solitario o imparcial. La narrativa expresa la dimensión emotiva de la experiencia, la complejidad, relaciones y singularidad de cada acción; frente a las deficiencias de un modo atomista y formalista de descomponer las acciones en un conjunto de variables discretas. Como modo de conocimiento, el relato capta la riqueza y detalles de los significados en los asuntos humanos (motivaciones, sentimientos, deseos o propósitos), que no pueden ser expresados en definiciones, enunciados factuales o proposiciones abstractas, como hace el razonamiento lógico-formal (Bolívar, Domingo y Fernández, 2001, p. 78).

\section{La narrativa imaginativa y su función en la educación}

Por ultimo, se expone la concepción de narrativa imaginativa que aporta Rorty y desde la cual se plantea la necesidad de entender que todas las comprensiones de la realidad, desde la literatura, hasta la poesía o las matemáticas, constituyen una narrativa que describe el mundo con un juego de lenguaje particular y que ninguna representa jerárquicamente la realidad tal como ella es.

No se halla muy alejado de Rorty y Dewey el planteamiento de Bruner (2003), respecto 
del papel de la imaginación en la producción de sentido, cuando afirma que:

Ese poder de construir realidad, propio del relato, se opera gracias a la imaginación metafórica [es el poder de la imaginación que] traslada nuestra producción de sentido más allá de lo banal, al reino de lo posible. Explora las situaciones humanas mediante el prisma de la imaginación (p. 24).

\section{Asegura Rorty (1991), que}

[...] lo que los románticos expresaban al afirmar que la imaginación, y no la razón, es la facultad humana fundamental en el descubrimiento de que el principal instrumento de cambio cultural es el talento de hablar de forma diferente respecto del mundo y sus instituciones, más que el talento de argumentar bien (p. 27).

Que la imaginación constituye un poderoso modo de transformación social, ya lo advertía Dewey ${ }^{5}$ cuando aseguraba que es un

5 La imaginación, usada en el sentido habitual, constituye tanto una facultad o poder abstracto, como un ejercicio propio de artistas; pero en la concepción deweyana señala anticipación y posibilidad futura. Sin embargo, no es un "ideal" -porque el ideal tiene la característica de ser una meta remota que invita a la quietud de la acción, y en su lugar constituye un goce mental que se ubica en un ámbito inalcanzable y opera como "analgésico para mitigar la sensación de una miseria que a pesar de todo perdura" (Dewey, The Middle Works, vol. 14, 187)- que crea una distancia entre la realidad presente y la meta futura, privando de sentido y "satisfacción válida y significativa" (Dewey, The Middle Works, vol. 14, 187) al presente y ponderando lo utópicamente inexistente. La imaginación, en cambio, ocupa un lugar primordial en la concepción general de lo estético y lo religioso en Dewey, en cuanto "es un rasgo esencial de la inteligencia arraigada al entorno" (Alexander, 1993, p. 371), porque "en el proceso de resolución de una situación problemática, despliega las posibilidades" (Dewey, The Later Works, vol. 10, 274) y "nos indica el camino hacia la mejor [y] explora nuevas relaciones y nuevas vías para la actividad" (Dewey, The Later Works, vol. 10, 350). La característica esencial de la imaginación es la de ir más allá de las condiciones del entorno inmediato y actuar como motivadora de la acción por tener recurso proyectivo que admite vislumbrar, no solo las consecuencias futuras de una acción, sino que permite configurar imágenes mentales que acercan a la experiencia vital de otra persona. Rorty por su parte, señala que esta es una gran noción en la filosofía de Dewey, porque al permitir pensar que la conformación de estas imágenes dan sentido al mundo, la imaginación permite proyectarse empáticamente o como simpatía, dada una situación, la imaginación hace posible "entrar en la situación de otros" (Fesmire, 2003, p. 66), pero también permite romper los límites de lo que nos ha sido enseñado, por eso Rorty (2007) afirma que, "solo la imaginación puede atravesar el caparazón de la convención" (p. 923), dado que es la imaginación la que permite vislumbrar distintas posibilidades y mediante la cual se puede entender lo actual a la luz de lo posible, de manera que el significado del presente es necesariamente ampliado (Fesmire, 2003, p. 67), operando de manera que amplía la percepción más allá del contexto y la vivencia inmediata. De acuerdo con Rorty (2009), la imaginación es la disposición humana que lanza al individuo más allá de sus propios límites identitarios, como en el caso de los místicos o los poetas, quienes

"el poder de movernos" (Dewey, The Later Works, vol. 9, 30). Thomas Alexander entiende la imaginación, según Dewey, como "una extensión del entorno al cual respondemos" (ver Thomas Alexander, John Dewey's Theory of Art, Experience and Nature. The Horizons of Feeling, Albany: State University of New York, 1993, p. 387). La define como "la capacidad de comprender lo actual a la luz de lo posible" (Alexander, John Dewey's Theory of Art, p. 371); en la medida en que la imaginación se arraiga en los eventos concretos, constituye una exploración creativa de posibilidades no presentes y en esa medida es un ensayo, "rehearsal" -como cuando los actores ensayan una obra antes de su presentación- que hace posible experimentar varios cursos de acción que derivan en la acción propiamente dicha. A propósito de la imaginación, en relación con la moral, ver la muy comprehensiva y explicativa versión de Steven Fessmire titulada Moral Imagination. Pragmatism in Ethics, publicada por Indiana University Press, Bloomington, 2003. 
[...] se cuentan entre los mayores genios imaginativos que contribuyeron al progreso moral e intelectual de los seres humanos [...] la experiencia mística es un modo de superar los límites de la lengua que se habla y llegar a la creación de un nuevo lenguaje, que a su vez lleva al progreso moral e intelectual (p. 28).

En el texto sobre la experiencia, a propósito de la imaginación en Dewey, tema que aparece tratado en LW 9, 3-35, se afirma que:

La imaginación está estrechamente relacionada con el misterio, porque habiendo cosas que no comprendemos o de las cuales no nos damos cuenta, se presentan mediante la imaginación como posibilidades y tienen el poder de movernos [...] se trata de una posibilidad muy particular que tiene el poder de lanzar adelante al que imagina hacia la actualización; en pocas palabras, la imaginación "proyecta al individuo hacia algo distinto de sí mismo; hacia la búsqueda, el descubrimiento creativo de modos de resolución que adquieren la fuerza necesaria como para convertirse en acto" (Patiño, 2010, p. 150).

Rorty enfatiza en lo que él llama la razón literaria, puesto que en la medida en que la literatura apela al sentimiento estético, se trata de una razón sensible, una razón que posibilita rebasar las fronteras del yo de modo que se comprenda el sufrimiento del otro. Es en este rebasamiento de las fronteras donde tiene lugar la apertura pragmática, porque tanto Dewey como Rorty, comprenden que en la habilidad de cooperar se encuentra "la misma significación espiritual que nuestros antepasados hallaron en un ser inmortal" (Rorty, 2000, p. 32). Se trata de una educación orientada hacia un arte -de allí el sentido estético- de vivir, el cual se constituye como arte por ser una creación intencional, radicalmente original y transformadora, fundada en la imaginación.

La educación por lo tanto, está llamada a contribuir al progreso moral de la humanidad y este progreso se traduce en el desarrollo de una consciencia de la solidaridad, desde narrativas que acercan al ser humano al sentimiento, a la sensibilidad; tal es el caso de los trabajos artísticos de Marina Abramovic, la literatura o el cine; en otras palabras, desde el campo educativo es necesario estructurar currículos y planes de estudios hacia la potenciación de una racionalidad compasiva, como metodología de lo que él llama la política utópica, mediante imaginación literaria, simbólica o visual, que conecte y potencie la identificación con el otro y su sufrimiento (Rorty 1991) y en consecuencia, inmunice ante la crueldad. En este sentido, Vásquez (2005) enfatiza la importancia que Rorty le da a la literatura, a la etnografía o al relato etnográfico, cuando afirma que "la razón literaria, en la medida en que es una razón estética es una razón sensible al sufrimiento del otro" (p. 12). Este tipo de racionalidad estética es imprescindible en nuestro contexto presente, en primer lugar porque es necesario aprender a trascendernos a nosotros mismos, y en segundo lugar, porque vivimos en una época en la cual la razón objetiva y la instrumental-tecnológica son el discurso aceptado, como se ha dicho, como único criterio válido.

En LW9 (pp. 3-58), Dewey declara que la trascendencia no es un ir más allá de este 
mundo, sino ir más allá de nosotros mismos, es la capacidad de un ser humano para experimentarse como parte de una totalidad más amplia. La experiencia de esta trascendencia implica, en primer lugar el reconocimiento de que nuestra vida plena se inserta en procesos más amplios en el espacio y el tiempo, a la luz de los cuales adquiere sentido de dirección y liberación. Este sentido de trascendencia posibilita experimentar un estado de conexión, es una experiencia de pertenecer. El sentido deweyano de trascendencia confiere significado a la vida, puesto que permite pensar que la vida individual es parte de un algo mayor a nosotros mismos; se trata de imaginarse empáticamente junto al otro en su sufrimiento, lo que admite la ampliación de lo que Rorty designa como "el círculo del nosotros", de modo que es posible el aumento de la cantidad de personas que son consideradas como parte de nuestro grupo, cada vez más ampliado. Al respecto relata Rorty (2009) que:

El ejemplo más obvio de esta ampliación es el cambio que se produjo cuando los ricos empezaron a considerar a los pobres como conciudadanos suyos, antes que personas cuyo lugar en la vida había sido decretado por Dios. Los ricos debieron dejar de pensar que en comparación con sus propios hijos los niños más desvalidos estaban destinados en cierto modo a tener vidas menos felices. Solo cuando llegaron a esa coyuntura pudieron empezar a considerar riqueza y pobreza como instituciones sociales modificables, antes que como partes de un orden inmutable (p. 26).

\section{Se trata de la superación del egoísmo grupal y el interés personal}

El abandono del egoísmo es de crucial importancia en la formación de los individuos. Pasar de una visión en la cual se piense solo en la posición del yo enfrentado a los otros, para transitar a una posición de asumir el rol de los demás, conlleva a una continua disminución del egocentrismo, a su superación. Wilber hace un interesante ejercicio en el cual demuestra la necesidad de incluir a los otros en el nosotros rortiano y asegura que, aunque las personas crezcan en edad, no necesariamente superan su egoísmo infantil. De manera que el proceso de formar para la solidaridad puede ser considerado como una incesante reducción del egoísmo.

Describe Wilber (1996) el modo como ocurre el proceso de desarrollo emocional de los individuos, el cual se caracteriza por una natural mengua en el pensar individualista, ya que en una primera fase el niño es radicalmente ególatra, por ser incapaz de diferenciarse del mundo y está seguro que su percepción es compartida por todas las personas. En una fase siguiente, cuando hace su aparición el 'yo conceptual', se opera en el individuo una reducción del narcisismo, pero sigue siendo egocéntrico, puesto que aún no le es posible apropiarse del papel de un otro.

Cuando es posible representarse a sí mismo en el papel de otro, es natural que la mirada egocéntrica experimente una radical transformación, en este momento se sufre una especie de apertura, para incluir a otros. Esta perspectiva constituye una ampliación de la mirada, un cambio paradigmático, al renunciar a las actitudes egocéntricas, puesto que 
se pasa a incluir al grupo con el que se comparten valores, creencias e interpretaciones de la realidad, pero se debe advertir que si bien supone la expansión desde el egocentrismo radical hacia una consideración del grupo, no se va más allá de él y, aunque se ha operado una expansión, se requiere de una expansión mayor. Por tanto, se comprende que: si alguien es parte de lo que entiendo por mi 'tribu', y comparte mis mitos, mis creencias, mi ideología, tendremos algo en común y por lo tanto será escuchado y tenido en cuenta. Sin embargo, si alguien pertenece a una cultura diferente, a un grupo diferente, si cree en algo diferente o profesa ideas diferentes, al no parecerse a mi grupo, no será tenido en cuenta ni escuchado. Para que haya una "actitud auténticamente universal y pluralista" se requiere que el individuo entienda a los demás como parte de su "yo expandido" de manera que los entienda imaginativamente como incluidos dentro de la descripción de su yo. En ese sentido, se comienza a pensar en lo bueno, no solo para el grupo sino para todos, se empieza a pensar de manera global, como si todos compartiéramos una identidad a pesar de las diferencias particulares. Pasar del egoísmo a esta perspectiva global, según Wilber (1996), requiere de un ejercicio imaginativo genuino, que permita superar los intereses privados del yo, que acepte entender que mis creencias, ideales e interpretaciones no son las únicas, y que es posible comprender a partir de una mirada global, en la cual el mundo está descentrado del yo y de lo mío, "que es un mundo que exige atención, respeto, compasión y convicción" (p. 254).

Por todo lo dicho anteriormente, las propuestas en educación precisan contener narrativas orientadas al ejercicio, a la práctica de la empatía mediante el relato estético, puesto que cada día somos más conscientes de que necesitamos ejercitarnos para aprender la solidaridad. Nos preparamos, casi rutinariamente, para un deporte, para una profesión, para una habilidad. ¿Cómo no prepararnos, ejercitarnos y adiestrarnos en la práctica del aprendizaje más importante: el arte de vivir y de entendernos como parte de una comunidad amplia llamada humanidad?

\section{ReFERENCIAS}

Alexander, T. (1987). John Dewey's Theory of Art, Experience, and Nature. The Horizons of Feeling. Albany, NY: State University of New York Press.

Bertalanffy, L. (2007). Teoría general de los sistemas. México D. F., México: Fondo de Cultura Económica.

Bolívar, A., Domingo, J., y Fernández, M. (2001). La investigación biográfico-narrativa en educación. Barcelona, España: La Muralla.

Bourdieu, P. (2003). El oficio del científico. Barcelona, España: Anagrama.

Brum, M. (2010). Reflexiones sobre la racionalidad instrumental. Recuperado de https://www.fing.edu.uy/catedras/disi/ DISI/pdf/Racionalidad.pdf

Bruner, J. (2003). La fábrica de historias. Derecho, literatura, vida. México, D. F., México: Fondo de Cultura Económica.

Castells, M. (2001). La era de la información. Economía, sociedad y cultura. El poder de la identidad. Vol. II. Barcelona, España: Siglo Veintiuno Editores.

Del Bravo, M. A. (2000). Ecofeminismo. Jaén, España: Editorial Universidad de Jaén.

Dewey, J. (1969-1972). The Early Works, 1882-1898. 5 vols. Ed. Boydston, J. A. 
Carbondale and Edwardsville, IL: Southern Illinois University Press.

Dewey, J. (1976-1983). The Middle Works, 1899-1924. 15 vols. Ed. Boydston, J. A. Carbondale and Edwardsville, IL: Southern Illinois University Press.

Dewey, J. (1981-1986). The Later Works, 19251953. 17 vols. Ed. Boydston, J. A. Carbondale and Edwardsville, IL: Southern Illinois University Press, Chicago.

De Sousa Santos, B. (2014). Epistemologías del Sur. Barcelona, España: Akal.

Ellul, J. (2003). La edad de la técnica. Madrid, España: Octaedro.

Fesmire, S. A. (2003). John Dewey and Moral Imagination. Pragmatism in Ethics. Bloomington, IN: Indiana University Press.

Habermas, J. (1986). Ciencia y técnica como ideología. Madrid, España: Tecnos.

Heidegger, M. (1994). Vorträge und Aufsätze. Tubinga, Alemania: Ed. Nesk.

Heidegger, M. (1997). Filosofía, ciencia y técnica. Santiago de Chile, Chile: Editorial Universitaria.

Horkheimer, M. (2002). Crítica de la razón instrumental. Madrid, España: Trotta.

Hospers, J. (1979). La conducta humana. Madrid, España: Tecnos.

Hottois, G. (1991). El paradigma bioético. Una ética para la tecnociencia. Barcelona, España: Anthropos.

Marcuse, H. (1993). El hombre unidimensional. México D. F., México: Planeta.
Patiño, M. J. (2010). Lo religioso, el sentido pleno de la experiencia en el proyecto filosófico de John Dewey. Bogotá D. C., Colombia: Editorial Pontificia Universidad Javeriana, colección Laureata.

Pinkola, C. (1998). Mujeres que corren con los lobos. Barcelona, España: Ediciones B. S. A.

Rorty, R. (1991). Contingencia, ironía y solidaridad. Barcelona, España: Paidós Ibérica.

Rorty, R. (2000). El pragmatismo, una versión. Antiautoritarismo en epistemología y ética. Barcelona, España: Ariel.

Rorty, R. (2007). Dewey and Posner on pragmatism and moral progress. U. Chi. L. Rev., 74(3), 915-927. Recuperado de https://chicagounbound.uchicago.edu/ cgi/viewcontent.cgi?referer=https:// scholar.google.com/\&httpsredir=1\&article $=5416 \&$ context $=$ uclrev

Rorty, R. (2009). Una ética para laicos. Madrid, España: Katz.

Vásquez, A. (2005). La realidad como narrativa exitosa y la filosofía como género literario. Limite, 1(13). Chile: Universidad de Tarapacá. Recuperado de http:// www.redalyc.org/html/836/83601301/

Weber, M. (2002). Economía y sociedad. México D. F., México: Fondo de Cultura Económica.

Wilber, K. (1996). Breve historia de todas las cosas. Barcelona, España: Kairós. 